\title{
Correction to: Complications of Body Contouring Surgery in Postbariatric Patients: A Systematic Review and Meta-Analysis
}

\author{
Azmi Marouf ${ }^{1} \cdot$ Hatan $_{\text {Mortada }^{2,3}}$
}

Published online: 6 December 2021

(C) Springer Science+Business Media, LLC, part of Springer Nature and International Society of Aesthetic Plastic Surgery 2021

\section{Correction to: Aesth Plast Surg}

https://doi.org/10.1007/s00266-021-02315-2

This article was updated to correct Reference 36.
Publisher's Note Springer Nature remains neutral with regard to jurisdictional claims in published maps and institutional affiliations.

The original article can be found online at https://doi.org/10.1007/ s00266-021-02315-2.

Hatan Mortada

Hatanmortada@gmail.com

Azmi Marouf

maroufazmi@gmail.com

1 Department of Surgery, Faculty of Medicine, King Abdulaziz University, Jeddah, Saudi Arabia

2 Division of Plastic Surgery, Department of Surgery, King Saud University Medical City, King Saud University, Riyadh, Saudi Arabia

3 Department of Plastic Surgery \& Burn Unit, King Saud Medical City, Riyadh, Saudi Arabia 